\title{
The Effect of Information Provision on Pro-Environmental Behaviors
}

\author{
Hyunsook Lee ${ }^{1}$, Kiyo Kurisu' ${ }^{2}$, Keisuke Hanaki ${ }^{1}$ \\ ${ }^{1}$ Department of Urban Engineering, The University of Tokyo, Tokyo, Japan \\ ${ }^{2}$ Research Center for Advanced Science and Technology, The University of Tokyo, Tokyo, Japan \\ Email: ${ }^{\text {hslee@gtck.re.kr }}$
}

Received 25 March 2015; accepted 22 May 2015; published 25 May 2015

Copyright (C) 2015 by authors and Scientific Research Publishing Inc.

This work is licensed under the Creative Commons Attribution International License (CC BY). http://creativecommons.org/licenses/by/4.0/

(c) (i) Open Access

\section{Abstract}

To reduce the environmental load of the household sector, it is important to enhance people's proenvironmental behaviors (PEBs). Information provision has been considered as one of the possible methods for fostering PEBs. However, previous studies have seldom discussed what type of information is most appropriate for the target behavior. Effective media through which to provide such information should be also discussed. In order to identify the most effective such information, as well as the effectiveness of free papers as media through which to disseminate it, environmental information regarding two behaviors-"My Cup" and "Carbon Cashbag"-was provided through online questionnaires and free papers. Even though the same information was provided in both sources, it was found that the effectiveness of the content depended on the target behavior and region. As lack of information was one of the barriers to "Carbon Cashbag" behavior, it was found that the provision of very basic information improved the intention and practice of the behavior. Higher scores for intention and practice were observed when information was provided through free papers, which could therefore be considered as effective media through which to deliver information about PEBs.

\section{Keywords}

Information Provision, Information Content, Media, Free Papers, Pro-Environmental Behaviors

\section{Introduction}

Promoting pro-environmental behaviors (PEBs) is one of the key issues in the ongoing attempt to build a sus-

*Corresponding author. 
tainable society. For several decades, trials have been conducted in an attempt to enhance PEBs in people's daily lives, and have helped to change people's awareness and behaviors. However, the actual practice rates of PEBs are still not high, and lower practice rates are particularly common among younger generations [1] [2].

Information provision has been considered as a possible method for the enhancement of PEBs. Several studies have investigated the effectiveness of various types of information, such as social/personal norms [3]-[5] and declarative/procedural knowledge [6]-[8]. However, these studies have seldom discussed which type of information is most appropriate for the target behavior. In addition to information content, the media through which to provide the information is another important issue. Various studies have tried to use mass media for information provision [9]-[11]. However, they have shown that information provision via mass media has a minimal effect on behavioral change and that its effectiveness cannot be maintained for a long period of time [12] [13]. Reference [14] compared the effects of three types of media (mass, local, and personal) on recycling behavior. They conclude that mass media can only affect "goal intention", but that local and personal media can have a direct impact on behavior.

With the above issues in mind, we attempted 1) to clarify the most effective information regarding two different PEBs and 2) to evaluate the effectiveness of the free paper, a widespread form of local media, as a possible medium of information provision for the enhancement of PEBs.

\section{Material and Methods}

\subsection{Information Provision through Online Questionnaires}

To achieve research aim 1, we decided to use an online questionnaire survey. Different information was provided to different groups, and the survey inquired about respondents' changes of intention. The questionnaire consisted of three parts: a) inquiries on the cognition and practice of the target behavior, b) provision of information about the behavior, and c) inquiries about behavioral intention changes.

\subsubsection{Selection of Target Behaviors}

We selected two target behaviors using the results of our previous study, in which we selected 58 daily PEBs and surveyed the practice rate of and reasons for each behavior in Seoul and Tokyo [1]. Among those 58 behaviors, we selected the target behaviors for the present study based on the following criteria: a) the behavior shows a relatively low practice rate $(<60 \%)$, b) lack of information determines the non-practice of the behavior, and c) the effect of information provision on the behavior can be easily tested over a short-term period. Two behaviors that fulfilled these criteria were selected: 1) use of one's own cup or tumbler at cafés, instead of disposable cups ("My Cup"; B27 in [1]) and 2) purchase of Carbon Cashbag products ("Carbon Cashbag"; B49 in [1]). "My Cup" behavior had a 59.1\% practice rate in the first study. The main reasons not to conduct the behavior were that respondents considered it "inconvenient" and "bothersome" [1], but this behavior was selected for the present study because it can easily be changed during a short period via information provision. The "Carbon Cashbag" program was begun by Korea's Ministry of Knowledge and Economy in 2008. When people buy environmentally friendly products with Carbon Cashbag labels, they gain points that are redeemable for various goods and services. The practice rate of this behavior was $28.9 \%$ in the first study. The main reason not to conduct the behavior was cited by respondents as "no recognition" [1], which indicates the important effects of information provision on PEBs. In addition, neither of these two behaviors requires equipment installation and both can be implemented within a short time period.

\subsubsection{Psychological Factors}

The content of the information provided in the questionnaire was chosen based on three psychological factors: risk arousal, knowledge, and descriptive norms.

"Risk arousal" is the enhancement of awareness through the provision of risk information with a pessimistic tone. The effects of risk arousal have been discussed in various studies [15]-[17]. Reference [15] proposed a "two-phase model" for environmental behaviors, in which two intention phases- "goal intention" and "implementation intention"- determine behavior. In his model, risk arousal is considered one of the determinants of goal intention.

According to [18], environmental knowledge can be categorized into three types: 1) declarative knowledge, 2) knowledge about procedure (i.e. action-related), and 3) effectiveness. Declarative knowledge is defined as 
knowledge about facts, such as knowledge about what global warming is. Knowledge about how to conduct behavior is called "procedure" knowledge, which is one of the key predictors of behavior [6]-[8]. Reference [8] showed that the combination of procedural and declarative information has significantly positive effects on recycling behavior. "Effectiveness" knowledge related to effects driven by behavior, such as knowledge that $\mathrm{CO} 2$ or fuel costs can be reduced by switching from a gasoline-fueled car to a hybrid car. This concept is similar to the combination of perceived effectiveness and benefit evaluation in [19] two-phase model, mentioned above. Reference [20] hypothesized that objective information about effectiveness can change people's perception of effectiveness, which inspires more efficient PEBs. They provided information about $\mathrm{CO}_{2}$ reduction driven by electricity savings and other environmental behaviors, and demonstrated that objective information about effectiveness raised people's PEB awareness.

According to [3], social norms are categorized as descriptive norms and injunctive norms. Descriptive norms are defined as the cognition of the behavior of others. This is reflected in people's behavior in response to the behavior of others. Reference [4] demonstrated the effect of descriptive and personal norms on recycling behavior and found that personal norms had a short-term effect, whereas descriptive norms worked more effectively in the long term. Reference [3] showed that the effect of descriptive norms was more significant than that of personal norms for recycling behaviors in public places.

\subsubsection{Information Design}

With the above information in mind, we designed three types of information for the two target behaviors: a) risk arousal, b) knowledge, and c) descriptive norms.

Regarding "My Cup", we provided information about waste generation and the lack of landfill sites in Seoul (as shown on Seoul's metropolitan homepage) as risk arousal information (A). The volume of waste reduction that results from using personal cups or tumblers instead of disposable cups [21] was provided as effectiveness information (B1), while a list of shops that provided discounted drinks to people who bringing personal cups or tumblers was provided as procedure information (B2). The practice rate $(59.1 \%)$ was provided as descriptive norm information (C).

Regarding "Carbon Cashbag," we provided information on the seriousness of greenhouse gas emissions in Seoul (as shown on Seoul's metropolitan homepage) as risk arousal information (A). Methods through which to accumulate Carbon Cashbag points (B3) and lists of Carbon Cashbag products on the market (B4) were provided as procedure information. We also provided declarative information (B5) due to the low degree of recognition of the Carbon Cashbag program. The practice rate (28.9\%) was also provided as descriptive norm information (C).

Details on the information provided in the study are found in Table 1.

Table 1. The numbers of survey respondents for through free paper.

\begin{tabular}{|c|c|c|c|c|c|c|c|c|c|c|}
\hline & & & $10 \mathrm{~s}$ & $20 \mathrm{~s}$ & $30 \mathrm{~s}$ & $40 \mathrm{~s}$ & $50 \mathrm{~s}$ & $60 \mathrm{~s}$ & Total & $\begin{array}{c}\text { Collection } \\
\text { Rate }\end{array}$ \\
\hline \multirow{6}{*}{ My Cup } & & Men & 7 & 21 & 27 & 10 & 1 & 0 & 66 & \multirow{6}{*}{$49.5 \%$} \\
\hline & $\begin{array}{l}\text { Intention } \\
(\mathrm{n}=101)\end{array}$ & Women & 1 & 19 & 13 & 1 & 1 & 0 & 35 & \\
\hline & & & $7.9 \%$ & $39.6 \%$ & $39.6 \%$ & $10.9 \%$ & $2.0 \%$ & $0.0 \%$ & $100.0 \%$ & \\
\hline & & Men & 2 & 12 & 14 & 4 & 1 & 0 & 33 & \\
\hline & $\begin{array}{l}\text { Practice } \\
(\mathrm{n}=50)\end{array}$ & Women & 0 & 12 & 5 & 0 & 0 & 0 & 17 & \\
\hline & & & $4.0 \%$ & $48.0 \%$ & $38.0 \%$ & $8.0 \%$ & $2.0 \%$ & $0.0 \%$ & $100.0 \%$ & \\
\hline \multirow{6}{*}{$\begin{array}{l}\text { Carbon } \\
\text { Cashbag }\end{array}$} & & Men & 3 & 11 & 23 & 10 & 1 & 1 & 49 & \multirow{6}{*}{$28.4 \%$} \\
\hline & $\begin{array}{l}\text { Intention } \\
(\mathrm{n}=74)\end{array}$ & Women & 0 & 13 & 9 & 3 & 0 & 0 & 25 & \\
\hline & & & $4.1 \%$ & $32.4 \%$ & $43.2 \%$ & $17.6 \%$ & $1.4 \%$ & $1.4 \%$ & $100.0 \%$ & \\
\hline & & Men & 2 & 3 & 5 & 3 & 0 & 0 & 13 & \\
\hline & $\begin{array}{l}\text { Practice } \\
(n=21)\end{array}$ & Women & 0 & 5 & 3 & 0 & 0 & 0 & 8 & \\
\hline & & & $9.5 \%$ & $38.1 \%$ & $38.1 \%$ & $14.3 \%$ & $0.0 \%$ & $0.0 \%$ & $100.0 \%$ & \\
\hline
\end{tabular}




\subsection{Behavior Changes after Information Provision}

In order to investigate respondents' behavior changes, an additional questionnaire was sent to the same respondents via e-mail nine weeks after the first questionnaire survey. Changes in the target behaviors were investigated via a four-item scale: "I did not try", "I tried once", "I tried two or three times", and "I tried over five times".

The surveys were conducted in Seoul from September 26 to October 10, 2011 and in Tokyo from May 10 to 17, 2012. There were 840 respondents for "My Cup" and "Carbon Cashbag" in Seoul and 555 respondents for "My Cup" in Tokyo.

\section{Information Provision through Free Papers}

Based on the results of the online questionnaire survey, we selected information that would be effective in fostering the target behavior. We chose a free paper as a medium through which to spread the information.

The Focus is the largest free daily newspaper ("free paper") in the Republic of Korea, with a circulation of 418,598 as of April 2012, and has been certified by Korea ABC Association. Free papers are tabloid newspapers distributed in public places such as bus or subway stations. A relatively new form of media, they have been around since 1999 in the Netherlands and are spreading quickly, mostly in Europe as well as in America [22]. In Korea, they have been increasing rapidly since 2002 [19]. The majority of readers are young people who use public transportation (Christopher, 2003; Wilcox, 2005 (as quoted in [19]). Furthermore, free papers can also be distributed to people who do not ordinarily read newspapers, which enhances the newspaper business (Beard, 2003; Goff, 2004 (as quoted in [19] [23]).

We decided to place the selected information on a page on which famous cartoons are placed in order to ensure its consumption by a wide variety of readers. The same information used in the online questionnaire survey appeared on that page for four days. Information about "My Cup" was shown February 20-22 and 24, 2012. Information about "Carbon Cashbag" was shown February 27-29 and March 2.

In order to analyze readers' perceptions and behaviors, a questionnaire survey was conducted. The questionnaire was prepared on a Google spreadsheet; the contact address was provided on the same page as the information. A short URL was prepared using the Google function, and the QR code was provided in order to maintain easy access to the questionnaire. To enhance people's replies and prevent the bias of selecting environment-focused people as respondents, we mentioned on the same page that we would provide remuneration (a coupon worth $20,000 \mathrm{KRW}$, or US \$19) to the respondents.

In the questionnaire, respondents' intentions regarding the target behavior were asked about, in addition to their socio-demographics. We also requested their participation in another short survey that would be held three weeks later. Remuneration was sent to all respondents via e-mail.

Three weeks after the initial survey, we sent e-mails to the respondents who were willing to take the additional survey, which was conducted for "My Cup" from March 26 to April 10, 2012, and for "Carbon Cashbag" from April 2 to 22, 2012. The respondents were asked about how their actual behaviors accorded with the target behaviors.

\section{Results and Discussion}

\subsection{Information Provision through Online Questionnaire Survey}

To determine the significance of the effect of information on behavior intention and practice, questionnaire answers were coded from 5 ("I want to do this very much") to 1 ("I never want to do this") for intention, and either 0 ("I did not try") or 1 ("I tried") for practice. Though answers regarding practice were originally obtained on a 5 -point scale, in order to handle the small sample number in a meaningful way, we ultimately decided to simply use 1 or 0 .

\subsection{1. "My Cup"}

1) Seoul

Figure 1 shows the average scores of 12 respondent groups for "My Cup" in Seoul. The table below the graphs shows the combinations of information provided to each group. The scores range from 1.0 to 5.0 for intention and from 0.0 to 1.0 for practice. 


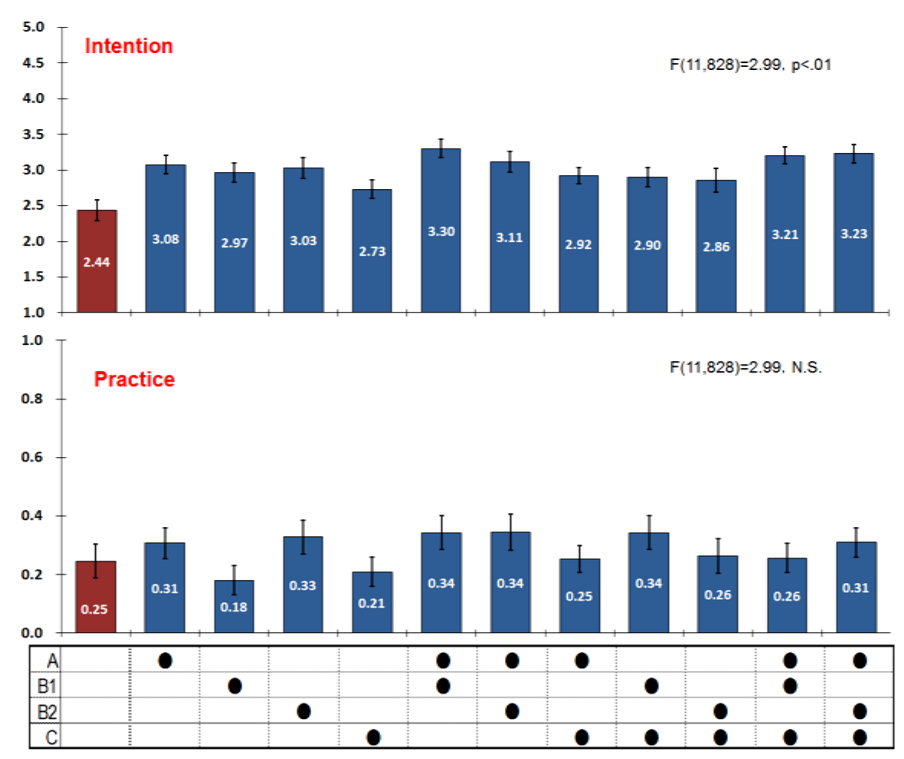

Figure 1. Intention and practice scores for "My Cup" in Seoul $(\mathrm{n}=840)$.

The group that was given no information had the lowest score (2.44) and the group to which risk arousal and effectiveness information was given had the highest (A + B1, 3.30). A tendency for scores to increase with information provision was observed. When a one-way-ANOVA test was applied to the intention results, a significant difference was found among the groups $(\mathrm{F}(11,828)=2.986, \mathrm{p}<0.01)$.

To identify significant differences among groups, we carried out a post-hoc (multiple comparison) test- Tukey-Kramer Hochberg's GT2 - as an analysis of equal-variance samples. Significant differences were found between [No Information] and [A + B1], between [No Information] and $[\mathrm{A}+\mathrm{B} 1+\mathrm{C}]$, and between [No Information] and $[\mathrm{A}+\mathrm{B} 2+\mathrm{C}](\mathrm{p}<0.01)$.

Regarding practice, five groups ([A], [A + B2 + C], [B1 + C], [A + B1], and [A + B2]) showed higher scores than the [No Information] group. In particular, the group to which risk arousal and effectiveness information was given had the highest score $(\mathrm{A}+\mathrm{B} 1,0.34)$. Yet, while this trend was observed, statistically significant differences were not observed, mainly due to the smaller sample size of each group $(F(11,828)=0.996, p=0.448$, $\mathrm{n}=70 \times 12$ groups).

2) Tokyo

Figure 2 shows the average scores of the 13 groups for "My Cup" in Tokyo. In addition to the 12-group set in Seoul, one additional group was given all of the information $[\mathrm{A}+\mathrm{B} 1+\mathrm{B} 2+\mathrm{C}]$ in Tokyo in order to analyze the effect of this combination.

The intention scores in Tokyo were relatively lower than those in Seoul. The [No Information] group had the lowest (1.78), and an upward trend was observed along with information provision. The same trend was observed in Seoul. Higher intention scores were seen in the $[A+B 1+C],[A+B 2+C]$, and $[A+B 1+B 2+C]$ groups $(2.92,2.91$, and 2.95 , respectively). In addition to the combination of risk arousal (A) and knowledge (B), the effect of descriptive norms (C) was significant in Tokyo, though not in Seoul. Significantly different intention scores were also found among the groups $(\mathrm{F}(12,542)=4.31, \mathrm{p}<0.001)$.

Dunnett's T3 was used as a post-hoc test due to the unequal variance of the samples. A significant difference from the [No Information] group was found for five groups: [A + B1], [A+B2], $[A+B 1+C],[A+B 2+C]$, and $[\mathrm{A}+\mathrm{B} 1+\mathrm{B} 2+\mathrm{C}](\mathrm{p}<0.05)$. The difference between $[\mathrm{A}+\mathrm{C}]$ and $[\mathrm{A}+\mathrm{B} 1+\mathrm{B} 2+\mathrm{C}]$ was also significant $(p=0.032)$. The tendency for the addition of knowledge information $(B 1, B 2)$ to increase intention scores was observed.

In the case of practice, [A] (0.15), [B1 + C] $(0.20),[\mathrm{A}+\mathrm{B} 1+\mathrm{C}](0.15),[\mathrm{A}+\mathrm{B} 2+\mathrm{C}](0.21)$, and $[\mathrm{A}+\mathrm{B} 1+$ $\mathrm{B} 2+\mathrm{C}](0.14)$ showed slightly higher scores than the [No Information] group $(0.05)$. The highest score was observed by $[A+B 2+C](0.21)$. Yet, although these trends were observed, the difference was not statistically significant $(\mathrm{F}(12,542)=1.33, \mathrm{p}=0.195)$.

3) Comparison between Seoul and Tokyo 


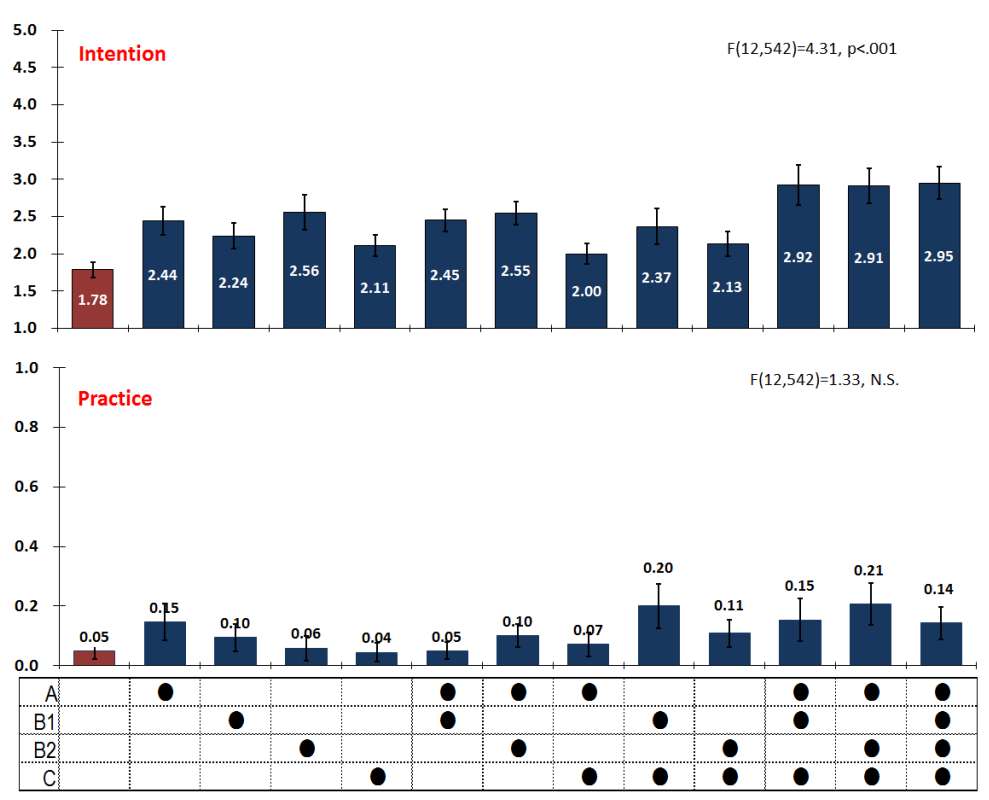

Figure 2. Intention and practice scores for "My Cup" in Tokyo $(\mathrm{n}=555)$.

Overall, the intention and practice scores in Seoul were higher than those in Tokyo. Our previous study also showed that the practice rate of "My Cup" in Seoul was significantly higher than that in Tokyo, which is attributed to the fact that intensive waste reduction programs, such as charging for waste bags, were begun earlier and have become more widespread in Korea than in Japan [1].

In terms of the influence of information provision, some differences between the two cities were observed. Risk arousal information [A] had more influence on intention in Seoul, while knowledge information [B] had more influence on intention in Tokyo. Based on the practice rate of "My Cup", we can assume that a lack of information acted as more of a barrier to practice in Tokyo than in Seoul. Yet, knowledge information was accepted more effectively, and had more influence on intention, in Tokyo.

\subsection{2. "Carbon Cashbag"}

Figure 3 shows the average scores of 16 groups for "Carbon Cashbag" in Seoul. In addition to risk arousal [A], and procedure [B3, B4] information, we also provided declarative information [B5] to all of the groups because the original degree of recognition of "Carbon Cashbag" was not high.

As seen in Figure 3, even when only declarative information was provided, respondents' intention to perform "Carbon Cashbag" behavior increased, and no statistical significance was observed among the groups (F $(15,1036)=1.176, p=0.284)$. In our previous survey [1], we revealed that the practice rate of "Carbon Cashbag" was quite low $(28.9 \%)$ and that one of the main reasons not to conduct the behavior was that respondents did not know about the behavior itself; therefore, it was indicated that people's intention would increase simply through declarative information provision. In addition, the combination of risk arousal, procedure, and descriptive norm information $[\mathrm{A}+\mathrm{B} 4+\mathrm{B} 5+\mathrm{C}]$ yielded a slightly higher intention score (4.07) than the other combinations.

In the case of practice, although the difference was not statistically significant $(\mathrm{F}(15,1036)=1.314, \mathrm{p}=$ $0.186)$, relatively higher scores were observed in groups $[\mathrm{B} 3+\mathrm{B} 5+\mathrm{C}](0.33),[\mathrm{B} 4+\mathrm{B} 5+\mathrm{C}](0.37),[\mathrm{B} 3+\mathrm{B} 4+$ $\mathrm{B} 5+\mathrm{C}](0.33),[\mathrm{A}+\mathrm{B} 3+\mathrm{B} 5+\mathrm{C}](0.34)$, and $[\mathrm{A}+\mathrm{B} 4+\mathrm{B} 5+\mathrm{C}](0.30)$.

\subsection{Information Provision through Free Papers in Seoul}

\subsubsection{Survey Design}

We selected the information that would be provided through the free paper Focus in Seoul on the basis of the above results. The information that yielded the highest intention scores, as well as relatively high practice scores, was selected; these were [A + B1] for "My Cup" and [A + B4 + B5 + C] for "Carbon Cashbag". The information was shown on the cartoon page - as explained in Section 2.3 and shown in Figure 4-using the same explanation text as in the online survey. The figures shown with the text were designed by a professional designer. 


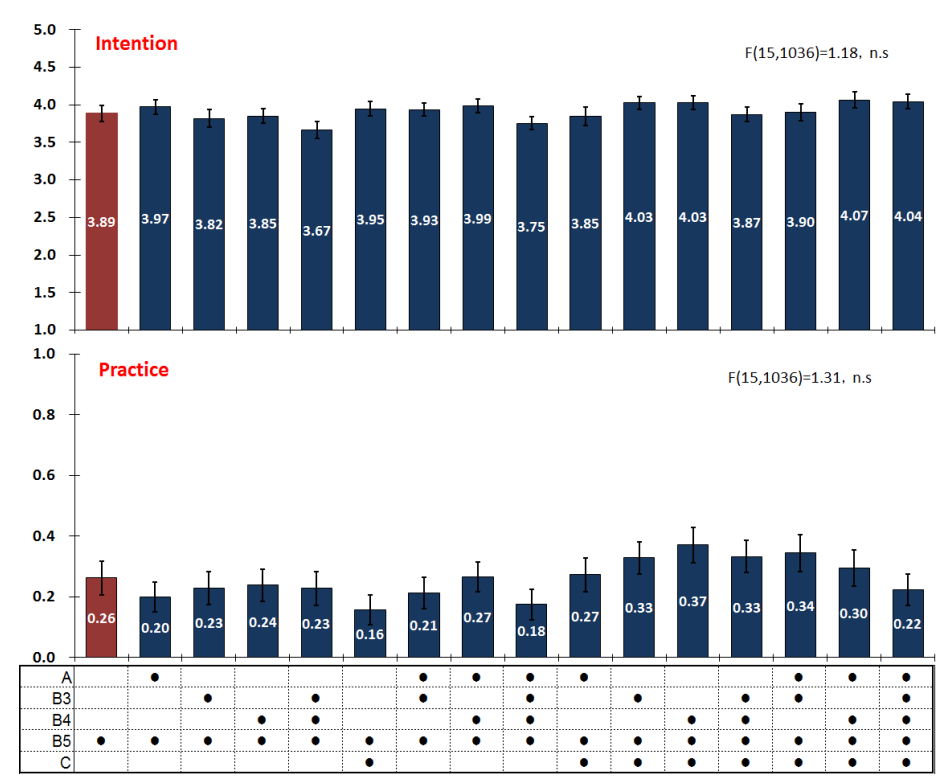

Figure 3. Intention and practice scores for "Carbon Cashbag" in Seoul $(\mathrm{n}=1052)$.

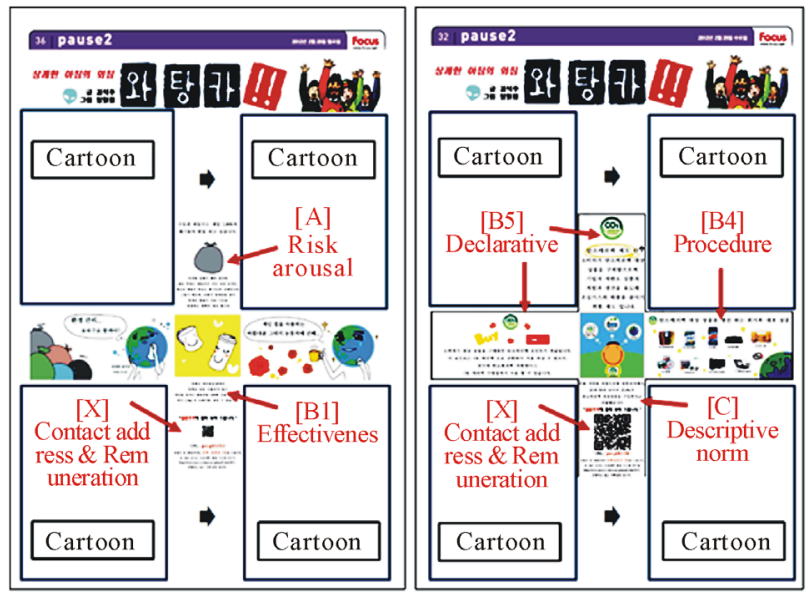

Figure 4. Information provision through Focus (Left: "My Cup"; Right: "Carbon Cashbag").

There were 101 respondents for the "My Cup" intention survey and 74 for "Carbon Cashbag". Fifty of the "My Cup" respondents and 21 of the "Carbon Cashbag" respondents took the additional survey about behavior practice three weeks later.

\subsection{2. "My Cup" Results}

In the "My Cup" survey, the average scores for intention and practice were $3.78(\mathrm{n}=101)$ and $0.40(\mathrm{n}=50)$, respectively. Respondents who answered the intention question with the responses "I want to do this very much", "I want to do this somewhat", and "I want to do this" $(\mathrm{n}=85)$ were also asked about the usefulness of the provided information. For instance, we asked questions such as, "Was the risk information useful to you," to which subjects responded on a 6-point scale, from 6 (very much) to 1 (not at all).

The results are shown in Figure 5. The average usefulness score was observed to be significantly higher for [A] (5.26) than for [B1] (5.13) $\left(\chi^{2}=88.34, \mathrm{df}=9, \mathrm{p}<0.001\right)$.

\subsection{3. "Carbon Cashbag" Results}

In the "Carbon Cashbag" survey, the average scores of intention and practice were $3.85(\mathrm{n}=74)$ and $0.43(\mathrm{n}=$ 
21), respectively. Respondents who answered the intention question with the responses "I want to do this very much", "I want to do this somewhat", and "I want to do this" $(n=65)$ were also asked about the usefulness of the provided information. The results are shown in Figure 6. The average usefulness score for [B5] (4.98) was significantly higher than for [B4] (4.83) and [C] (4.52) $\left(\chi^{2}\right.$-test, $\left.p<0.001\right)$. This result again indicates that descriptive information can be useful for increasing intention, especially for behavior to which lack of basic information is a barrier.

\subsection{Discussion}

Figure 7 and Figure 8 show the results of information provision through the online questionnaire and the free paper. In the case of the free paper, we could not control the age and gender distribution of the respondents. Therefore, in addition to the results shown in Section 3.1, in which the distribution of the respondents was
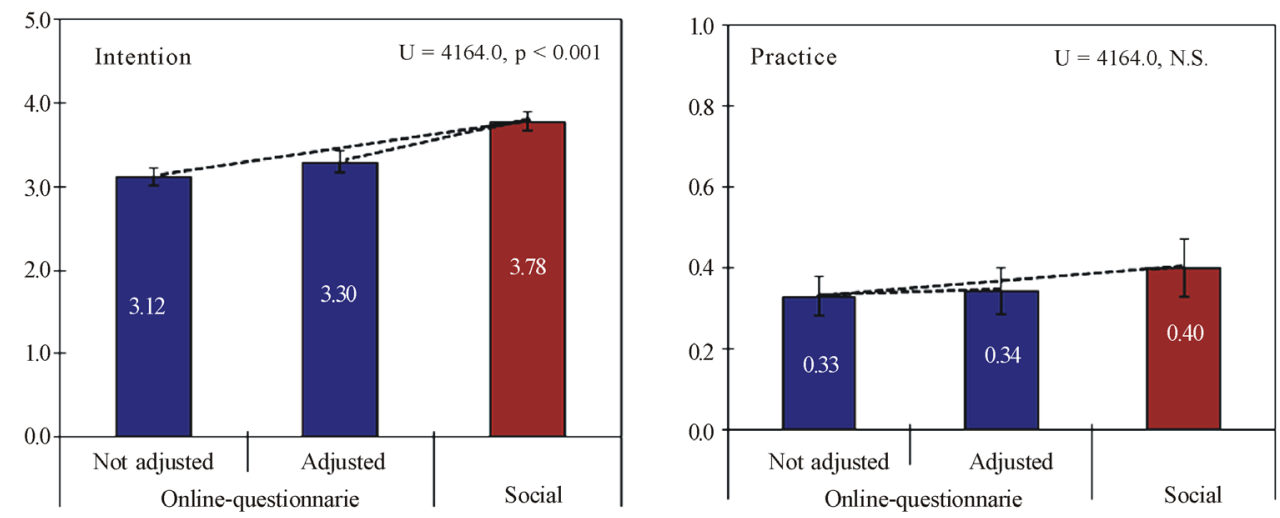

Figure 5. Information effectiveness for "My Cup".
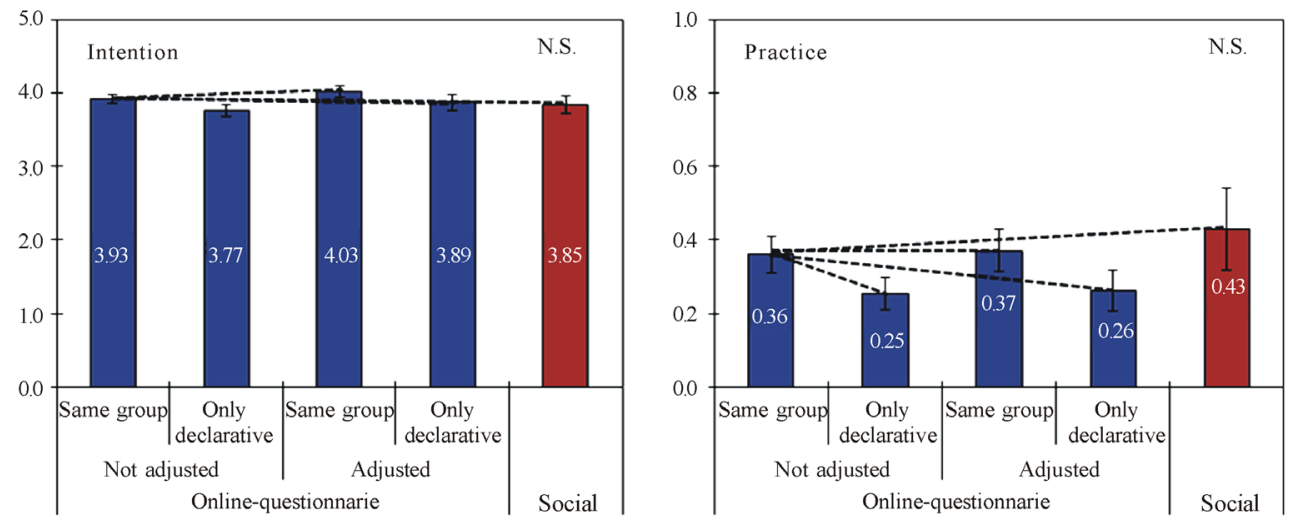

Figure 6. Information effectiveness for "Carbon Cashbag".

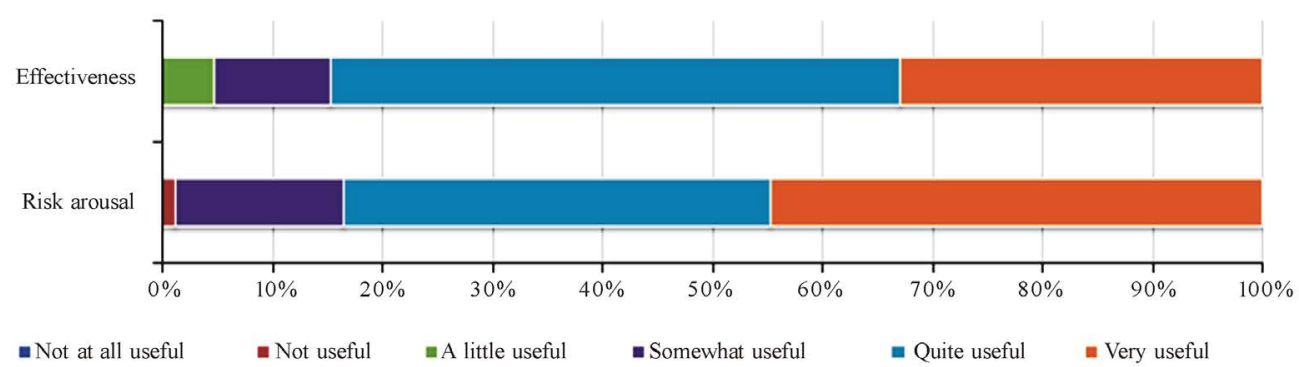

Figure 7. Information provision effects of "My Cup" through online questionnaire and free paper. 


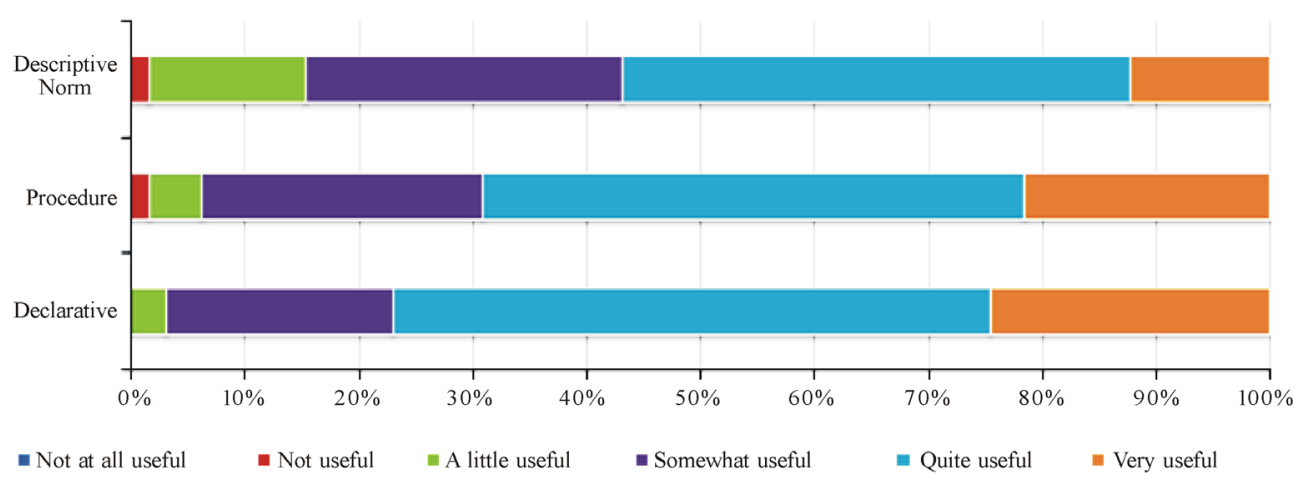

Figure 8. Information provision effects of "Carbon Cashbag" through online questionnaire and free paper.

adjusted to the parent population ("adjusted"), we also show the score obtained by the entire group of respondents ("not adjusted").

As shown in Figure 7, a significantly higher intention score for "My Cup" was observed when information was provided through the free paper rather than the online questionnaire (Mann-Whitney, $\mathrm{U}=4164.0$ (not adjusted), $\mathrm{p}<0.001$ ). A statistically insignificant but slightly higher practice score was also observed in the case of free paper access.

On the other hand, for "Carbon Cashbag" (Figure 8), there was no significant difference in intention between online and free paper access (Mann-Whitney, $U=4610.5$ (not adjusted, same group), $p>0.10$ ). However, a slightly higher practice score was observed in the case of free paper access.

The possible reasons for the difference in results between the online questionnaire and the free paper are a) design effect, b) information source, and c) difference in media.

Reference [24] reviewed the effects of information form and indicated that a picture more significantly affects people's information recognition than a text. This could also affect the difference between the online questionnaire, in which information was given in text form only, and the free papers, which included images.

In order to prevent anxiety among the respondents, we included the name of our organization (The University of Tokyo) in the free papers, whereas it was not included in the online questionnaire. The provision of the informer name might have increased the respondents' sense of the reliability of the provided information. According to [25], people judge the reliability of website information on the basis of the domain name. Other previous studies [26] [27] have also shown that the sender's information has an effect on the receiver's reliability perception regarding risk recognition. Therefore, even though the organization name was provided in a small font size at the end of the text, its presence might have had an influence on people's intentions.

Reference [28] and [29] compared the memorability and recognition of article importance between the use of the "print version" and the "web version" of ChosunIlbo, the most popular newspaper in Korea. Recognition and memorability were shown to be significantly higher when the information was provided through the newspaper. Reference [30] compared the effectiveness of a physical activity between web-based and printed materials for adolescent girls. Both web-based and printed materials showed significant effectiveness, but the print group showed more of an increase in intention than did the web group. Thus, the difference between types of media can be one of the most influential factors in information processing. The higher intention and practice scores of the free papers in our study also indicated the capability of free papers to be an effective medium through which to provide information that fosters people's pro-environmental intentions and behaviors.

Table 1 shows the composition of respondents discussed in Section 3.2. Younger people $(20 \mathrm{~s}$ and $30 \mathrm{~s})$ and men tended to respond more than elderly people and women. As mentioned above, younger people and men usually have lower practice rates for PEBs. Therefore, free papers can be considered an effective medium for the delivery of information to people who have previously been unconscious of PEBs.

\section{Conclusion}

We investigated the effects of information provision for two PEBs: "My Cup" and "Carbon Cashbag". The effects of various combinations of information were significantly different between the two behaviors and also 
between the two survey sites, Seoul and Tokyo. If lack of information is one of the barriers to a behavior such as "Carbon Cashbag", even very basic information can play a significant role in enhancing the intention and practice of the behavior. In choosing information content, understanding the current barriers or accelerators for the target behavior is an important first step toward designing an effective program. Free papers, which facilitate a higher increase in intention and practice than online questionnaires, can be considered as an effective medium through which to deliver information about PEBs to non-environmentally-conscious people.

\section{References}

[1] Lee, H., Kurisu, K. and Hanaki, K. (2013) Influential Factors on Pro-Environmental Behaviors-A Case Study in Tokyo and Seoul. Low Carbon Economy, 4, 104-116. http://dx.doi.org/10.4236/lce.2013.43011

[2] Kurisu, K.H. and Bortoleto, A.P. (2011) Comparison of Waste Prevention Behaviors among Three Japanese Megacity Regions in the Context of Local Measures and Socio-Demographics. Waste Management, 31, 1441-1449. http://dx.doi.org/10.1016/j.wasman.2011.03.008

[3] Cialdini, R.B., Reno, R.R. and Kallgren, C.A. (1990) A Focus Theory of Normative Conduct: Recycling the Concept of Norms to Reduce Littering in Public Places. Journal of Personality and Social Psychology, 58, 1015-1026. http://dx.doi.org/10.1037/0022-3514.58.6.1015

[4] Schultz, P.W., Nolan, J.M., Cialdini, R.B., Goldstein, N.J. and Griskevicius, V. (2007) The Constructive, Destructive, and Reconstructive Power of Social Norms. Psychological Science, 18, 429-434. http://dx.doi.org/10.1111/j.1467-9280.2007.01917.x

[5] Schultz, P.W. (1999) Changing Behavior with Normative Feedback Interventions: A Field Experiment on Curbside Recycling. Basic and Applied Social Psychology, 21, 25-36. http://dx.doi.org/10.1207/s15324834basp2101 3

[6] Frick, J., Kaiser, F.G. and Wilson, M. (2004) Environmental Knowledge and Conservation Behavior: Exploring Prevalence and Structure in a Representative Sample. Personality and Individual Differences, 37, 1597-1613. http://dx.doi.org/10.1016/j.paid.2004.02.015

[7] Hornik, J., Cherian, J., Madansky, M. and Narayana, C. (1995) Determinants of Recycling Behavior: A Synthesis of Research Results. The Journal of Socio-Economics, 24, 105127. http://dx.doi.org/10.1016/1053-5357(95)90032-2

[8] Iyer, E.S. and Kashyap, R.K. (2007) Consumer Recycling: Role of Incentives, Information, and Social Class. Journal of Consumer Behaviour, 6, 32-47. http://dx.doi.org/10.1002/cb.206

[9] Slovic, P. (1986) Informing and Educating the Public about Risk. Risk Analysis, 6, 403-415. http://dx.doi.org/10.1111/j.1539-6924.1986.tb00953.x

[10] Staats, H.J., Wit, A.P. and Midden, C.Y.H. (1996) Communicating the Greenhouse Effect to the Public: Evaluation of a Mass Media Campaign from a Social Dilemma Perspective. Journal of Environmental Management, 46, 189-203. http://dx.doi.org/10.1006/jema.1996.0015

[11] Davies, A.R. (2008) Civil Society Activism and Waste Management in Ireland: The Carranstown Anti-Incineration Campaign. Land Use Policy, 25, 161-172. http://dx.doi.org/10.1016/j.landusepol.2007.04.002

[12] Driedger, S.M. (2007) Risk and the Media: A Comparison of Print and Televised News Stories of a Canadian Drinking Water Risk Event. Risk Analysis : An Official Publication of the Society for Risk Analysis, 27, 775-786. http://dx.doi.org/10.1111/j.1539-6924.2007.00922.x

[13] Hirose, Y. (2008) コミュニケーションにより環境行動を広める(Extend the Pro-Environmental Behavior through Communication). In: Hirose, Y., Ed., 境行動の社会心理学 (Social Psychology of Pro-Environmental Behavior), Kitaohjisyobou, 52-61.

[14] Nonami, H., Sugiura, J., Ohnuma, S., Yamakawa, H. and Hirose, Y. (1997) 資源リサイクル行動の意思決定におけ る多様なメディアの役割--パス解析モデルを用いた検討 (The Roles of Various Media in the Decision Making Processes for Recycling Behavior-A Path Analysis Model). The Japanese Journal of Psychology, 68, $264-271$. http://dx.doi.org/10.4992/jjpsy.68.264

[15] Hirose, Y. (1994) 環境配慮的行動の規定因について(Determinants of Environment-Conscious Behavior). 社会心 理学研究(The Japanese Society of Social Psychology), 10, 44-55.

[16] Owens, S. (2000) "Engaging the Public": Information and Deliberation in Environmental Policy. Environment and Planning A, 32, 1141-1148. http://dx.doi.org/10.1068/a3330

[17] Jensen, B.B. (2002) Knowledge, Action and Pro-Environmental Behaviour. Environmental Education Research, 8, 325-334. http://dx.doi.org/10.1080/13504620220145474

[18] Kaiser, F.G. and Fuhrer, U. (2003) Ecological Behavior's Dependency on Different Forms of Knowledge. Applied Psychology, 52, 598-613. http://dx.doi.org/10.1111/1464-0597.00153 
[19] Yi, K., and Sung, Y. (2007) What to Read in the Morning? A Niche Analysis of Free Daily Papers and Paid Papers in Korea. International Journal on Media Management, 9, 164-174. http://dx.doi.org/10.1080/14241270701634155

[20] Ohta, H. and Fuji, S. (2007) 環境配慮行動における客観的 $\mathrm{CO}_{2}$ 排出削減量事実情報提供の効果に関する実験研 究 (An Experimental Study on Effects of Providing Objective Information about Reduction of $\mathrm{CO}_{2}$ Emission Due to Pro-Environmental Behavior). Journal of Japan Society of Civil Engineers, 63, 159-167.

[21] Shimpo, Y., Nakatani, J., Kurisu, K. and Hanaki, K. (2012) 家庭における廃棄物発生抑制行動のライフサイクル 評価(Life-Cycle Assessment of Household Waste Prevention Behaviors). Japanese Journal of Society of Environmental Science, 25, 95-105.

[22] Bakker, P. (2002) Free Daily Newspapers-Business Models and Strategies. International Journal on Media Management, 4, 180-187. http://dx.doi.org/10.1080/14241270209389998

[23] Picard, R.G. (2001) Strategic Responses to Free Distribution Daily Newspapers. International Journal on Media Management, 3, 167-172. http://dx.doi.org/10.1080/14241270109389962

[24] Levie, W.H. and Lentz, R. (1982) Effects of Text Illustrations: A Review of Research. Educational Technology Research and Development, 30, 195-232.

[25] Ohsaku, M. and Kamikado, H. (2007) Literacy Relating to the Proper Use for the Data, Which Exist on Web Sites. The Japanese Journal of Multimedia Education Research, 13, 55-68.

[26] Eiser, J.R., Miles, S. and Frewer, L.J. (2002) Trust, Perceived Risk, and Attitudes toward Food Technologies1. Journal of Applied Social Psychology, 32, 2423-2433. http://dx.doi.org/10.1111/j.1559-1816.2002.tb01871.x

[27] Rosati, S. and Saba, A. (2004) The Perception of Risks Associated with Food-Related Hazards and the Perceived Reliability of Sources of Information. International Journal of Food Science and Technology, 39, 491-500. http://dx.doi.org/10.1111/j.1365-2621.2004.00808.x

[28] Kim, M.-K. and Lee, T.-H. (2006) 정보전달형식의차이가뉴스수용행위에미치는영향-조선일보와조선닷컴을중심으로 (Effects on Readers by the Difference of Presentation Formats: Focusing on ChosunIlbo and Chosun.com). Korean Journal of Communication Science, 6, 37-64.

[29] Kweon, S.-G. and Kim, W.-G. (2004) 뉴스메시지처리에있어서온라인미디어수용자와오프라인미디어수용자의차이 (Differences between On-Line and Off-Line Media Audience's News Message Processing). Korean Journal of Journalism and Communication Studies, 48, 168-194.

[30] Marks, J.T., Campbell, M.K., Ward, D.S., Ribisl, K.M., Wildemuth, B.M. and Symons, M.J. (2006) A Comparison of Web and Print Media for Physical Activity Promotion among Adolescent Girls. The Journal of Adolescent Health: Official Publication of the Society for Adolescent Medicine, 39, 96-104. http://dx.doi.org/10.1016/j.jadohealth.2005.11.002 